\title{
Spanish Interference in EFL Writing Skills: A Case of Ecuadorian Senior High Schools
}

\author{
Paola Alexandra Cabrera Solano ${ }^{1}$, Paul Fernando Gonzalez Torres ${ }^{1}$, Cesar Augusto Ochoa Cueva ${ }^{1}$, Ana Lucia \\ Quinonez Beltran ${ }^{1}$, Luz Mercedes Castillo Cuesta ${ }^{1}$, Lida Mercedes Solano Jaramillo ${ }^{1}$, Franklin Oswaldo \\ Espinosa Jaramillo ${ }^{1} \&$ Maria Olivia Arias Cordova ${ }^{1}$ \\ ${ }^{1}$ Universidad Tecnica Particular de Loja, Ecuador \\ Correspondence: Paola Alexandra Cabrera Solano, Universidad Tecnica Particular de Loja, Ecuador. E-mail: \\ pacabrera@utpl.edu.ec
}

Received: March 7, 2014 Accepted: May 20, 2014 Online Published: June 13, 2014

doi:10.5539/elt.v7n7p40 URL: http://dx.doi.org/10.5539/elt.v7n7p40

\begin{abstract}
Extensive studies have been conducted regarding mother tongue (L1) interference and developing English writing skills. This study, however, aims to investigate the influence of the Spanish language on second language (L2) writing skills at several Ecuadorian senior high schools in Loja. To achieve this, 351 students and 42 teachers from second year senior high schools (public and private) were asked to participate in this study. The instruments for data collection were student and teacher questionnaires, as well as a written test in which students were asked to write a narrative passage. The information gathered from the instruments was then organized and tabulated to determine the various interference variables. Afterwards, the most representative samples from the narrative texts were analyzed based on their semantic, morphological and syntactical features. The results from this study indicate that English grammar and vocabulary were the linguistic areas that suffered the highest level of L1 language interference. The most common Spanish interference errors were misuse of verbs, omission of personal and object pronouns, misuse of prepositions, overuse of articles, and inappropriate/ unnatural word order. Finally, some suggestions are given to teachers in order to help students prevent further Spanish interference problems during writing/composition classes.
\end{abstract}

Keywords: mother tongue interference, EFL learners, writing skills, interference errors, second language

\section{Introduction}

English in Ecuador is taught as a Foreign Language in school, so teachers and students are exposed to their native language most of the time. This situation causes interference of the mother tongue at the moment of learning the English language. This interference problem is evident when using productive skills, especially in conveying written messages.Consequently, Ecuadorian students use Spanish written structures when writing English texts. It is also common for students to translate word for word from Spanish into English. As a result, L1has a negative influence when writing in English (Lopez, 2011). This transfer of structures and vocabulary from L1 to L2 is a phenomenon that the present study intends to analyze.

The awareness of the mother tongue interference in the teaching-learning process is an important aspect that can contribute to an effective communication in the English language. Additionally, it is essential to achieve an effective communication through the integration of all four language skills (reading, writing, listening, and speaking) due to the fact that the main objective of teaching and learning any language is the integration of the linguistic skills that develop communicative competence with an emphasis on real life situations (Akram \& Malik, 2010).

Among these four skills, writing is often considered an indispensable skill that enables students to develop an appropriate level of linguistic competence. According to Harmer (2004), writing helps students to express their ideas in written form and to achieve a high level of communication. In the Ecuadorian context, writing in English as a foreign language constitutes a primary concern for high school students because they need this skill in their academic life (e.g. studying abroad, understanding academic information, etc.). However, producing a coherent, fluent and extended piece of writing is the most difficult activity to do in language learning, especially in a second or, in this case, a foreign language (Nunan, 1999). 
As it was previously mentioned, the interference of the mother tongue is a factor that hinders the development of the writing skill in the foreign language, which can produce a negative effect on language learning. In this respect, Bhela (1999) explains that in the event that learners do not know syntactical structures in their second language (L2), they use syntactical items of their first language (L1) to adapt their L2 written utterances. However, none of these studies have been conducted at a local level in Loja, Ecuador. This is another reason why research on Spanish interference in EFL writing skills has been considered for this study. It is important to mention that the results gathered from this study will be able to help teachers and students to be aware of the interference errors and, consequently, avoid them in order to improve the English language teaching learning process.

This study aims to investigate the influence of the Spanish language on L2 writing skills at several Ecuadorian senior high schools in Loja. Considering the significance of this problem for EFL learners in Ecuador, this study also seeks to identify the most common L1 interference errors in the written English of high school students. Moreover, it provides teachers with some classroom activities and strategies that could help prevent L1 interference.

\section{Literature Review}

\subsection{Writing in EFL}

Writing is a skill that demands great effort and commitment. For this reason, it is often difficult for students to master this skill in a foreign language. József (2001) claims "writing is among the most complex human activities because it involves the development of a design idea, the capture of mental representations of knowledge, and of experience with subjects." Without doubt, writing is considered a challenging task even in one's mother tongue. According to Harmer (2004), being able to write is just as vital for "speakers" of a foreign language as it is for others who speak their native tongue. Despite the fact that writing is not learned naturally and needs to be systematically taught, it is essential for communication. For this reason, it constitutes a fundamental aspect of Teaching English as a Foreign Language (TEFL) courses.

Conversely, Kroll (2003) argues "there is a demand today for teachers with a high level of pedagogical understanding and expertise in the different aspects of writing instruction, from curriculum development, to classroom pedagogy, to assessment." Consequently, teachers should remain informed of these aspects of the teaching-learning process and acquire expertise in EFL writing instruction. One of the key problem areas is the therefore mother tongue interference, which is the tendency of the learners to apply the rules of the native language since they do not know the structures of the target language (Alonso, 1997).

\subsection{Mother Tongue Interference}

Research on L2 interference has shown that foreign language learners tend to be highly dependent on L1 structures and vocabulary, especially when producing suitable responses in the target language. Beardsmore (1982) explains that many of the difficulties foreign language learners have with the lexicon and grammar of the target language are caused by the transfer of linguistic habits from the native language, which leads to errors and mistakes. It is important to highlight that there is a clear distinction between errors and mistakes. Ellis (1997) establishes that errors reveal gaps in the learner's knowledge. These errors mainly occur because the learner does not have a good command of the foreign language. On the other hand, mistakes reflect occasional lapses in performance. Interestingly, these transfer errors repeatedly occur in the four English language skills. Language transfer, however, is not always negative. It can be positive as well. Positive transfer occurs when the similarities between the mother tongue and the target language help learners acquire L2. Conversely, negative transfer takes place when the differences between the mother tongue and the target language cause errors when learning L2. It can be said that similarities can undermine students' acquisition of the target language, for example, by using false cognates/false friends (Calvo, 2005).

With regard to writing skills, most of the errors that occur in L2 writing are related to the transfer of grammatical structures (Alonso, 1997). This suggests that the mother tongue is the main cause of interference when writing in a foreign language and the main influence at a psycholinguistic level, in other words, thinking in the mother tongue.

It is also important to know what types of mother interference errors occur in EFL writing. This aspect is tackled by Berthold, Mangubhai and Batorowicz (1997), who define grammatical interference as the L1's influence on the L2, namely in terms of word order, pronoun and determinant usage, verb tense, and mood. They also state that interference at a lexical level refers to the borrowing of words from one language and attempting to make them sound more natural in the L2. Additionally, there is orthographic interference, which involves altering the 
spelling of one language and applying it to another one.

Similarly, Dam (2010) explains that Spanish-speaking English language learners make interference errors by borrowing patterns from their mother tongue. He provides various types of typical interference errors such as articles, gender, number, personal pronouns, relative pronouns, adjectives, prepositions, possessives, question formation, negation, verb tenses, passive voice, word order, and false cognates.

\subsection{Previous Studies}

Some studies on mother tongue interference in English writing have been conducted. Bhela (1999), in a study conducted on adult native speakers of different languages (Vietnamese, Cambodian, Italian and Spanish), asked four students to write stories in their native language and in English. The analysis of the written texts demonstrated that learners frequently use structures from the mother tongue when producing structures in the target language. As a result, both acceptable and inappropriate texts were produced in English.

In another study, Watcharapunyawong and Usaha (2013) analyzed writing errors which were found in three different text types: narration, description, and comparison/contrast. In this case, one hundred and twenty English paragraphs written by 40 second year English major students were analyzed by using Error Analysis (EA). As a result, the interference errors of the Thai language into English were categorized by text type. Additionally, the results of this study conclude that L1 interference categories of each writing genre varied in terms of L1 syntactic and semantic properties.

A study about interlingual and intralingual interference in EFL, carried out by Kaweera (2013), illustrates some frequent errors normally found in the English writing of a group of Thai students. The analysis of these errors was based on lexical, syntactic and discourse interference aspects. The results show that mother tongue interference and limited linguistic knowledge may be crucial factors in the students' successful acquisition of writing skills in their target language.

Lopez (2011) investigated the influence L1 written structure has on L2 written structure. For this purpose, twenty four students were asked to write some papers in English during one semester. Based on the analysis of these written texts, the results indicated that the influence of L1 (Spanish) can definitely hinder the writing processes in $\mathrm{L} 2$.

\section{Method}

\subsection{Participants}

In order to determine the sample for this study, statistical information related to number of high schools, geographical location, and number of students enrolled was gathered from the Ecuadorian Ministry of Education. According to this government body, the total number of students in the second year of senior high schools in the city of Loja for the academic year 2012-2013 totaled 4092.

The sample selected for this study consisted of 351 students from the second year of senior high school in Loja -i.e. the sample was taken from both public and private institutions. The sample size was established by using statistical formulae. Additionally, one English teacher from each high school participated in this research, which provided a total of 42 (18 male and 24 female) teachers. The students chosen for this sample were 139 male and 212 female aged between 15 and 18 .

\subsection{Materials}

The following instruments were designed considering the specific objectives of this study:

1) A student's questionnaire consisting of eleven questions. This focused on general and background information related to English language instruction. The questions dealt with aspects such as students' learning preferences during writing and other aspects related to the way they learn English.

2) A written test in which students were asked to write a narrative passage about any story of their childhood. Students were advised to write the main idea, the supporting ideas and a concluding sentence. Moreover, the students were given 20 minutes to write the paragraph (there was a minimum word limit of 100 words and a maximum of 150 words for this).

3) A teacher's questionnaire consisting of sixteen questions. This instrument was designed to obtain quantitative information related to the methods and activities used when teaching writing and the types of interference errors that teachers consider students made when writing in English. This questionnaire was based on general and background information about teachers, teacher's instruction, teacher's feedback, and aspects such as teaching writing skills and L1 interference. 


\subsection{Procedure}

The statistical method used for this study is based on concepts of descriptive statistics, particularly, frequency distribution and random sampling. Teddlie and Yu (2007) explain that random sampling gives an equal chance to the population of being included in a sample and the probability is not affected. Based on this theory, a sample of the students was randomly selected so as to obtain the information. Then, we visited schools to apply the questionnaires and to get the students to respond to a questionnaire and then to get them to write a narrative text about their childhood. High school English teachers were also randomly selected to respond to the teachers' questionnaire.

Afterwards, the information was organized and tabulated to determine and analyze the interference variables. For this purpose, a table containing all the questions and variables of the instruments was designed in order to count the number of occurrences of the responses. Once the frequencies (number of occurrences of each response) were established, the percentages were calculated.

\subsection{Data Analysis}

This study was based on mixed methods research (quantitative and qualitative) for analyzing the information that was gathered. With respect to the quantitative data, all of the questions in the teachers' and students' questionnaire were tabulated using tables in Excel containing the questions and variables of the instruments for collecting data; the corresponding frequencies and percentages were then calculated. These tables were interpreted based on their results. This information was subsequently used to write a handout about teaching strategies for reducing and preventing further $\mathrm{L} 1$ interference.

The written texts were analyzed by counting and classifying the interference errors into categories in order to determine which interference errors were produced by the students, i.e.to obtain the variables for the study. The results were represented as a figure, indicating the most frequent Spanish interference errors made by students. (See Fig. 1).

The qualitative method was also used. Hancock, Ockleford and Windridge (2009) state "qualitative research is concerned with the opinions, experiences and feelings of individuals producing subjective data." In this case, we used a qualitative approach called content analysis, which according to the aforementioned authors, has an emphasis on the analysis of texts. In this phase, the most frequent interference errors from the written texts were linguistically analyzed by considering their semantic, syntactic and morphological features. For the purpose of this study, the most representative sentences with errors were selected and analyzed individually.

\section{Results}

After applying the frequency distribution of the data gathered in Excel tables, the results were the following:

The information from the students' questionnaire indicated that the usage of grammar structures and vocabulary are the most challenging areas for Ecuadorian students writing in English. As far as the strategies that the students used when writing in English, the results showed that 76\% think in Spanish first and then translate their ideas into English. Unfortunately, only 18\% write directly in English without translating. The remaining 6\% avoided answering this question. These results demonstrated that the mother tongue produced significant interference when students write in the target language.

For the teachers' questionnaire, $78 \%$ of respondents reported that one of the key strategies that their students use when writing in English is to first think in Spanish and then translate their ideas into English.

In addition, there were diverse responses to the variables regarding the level of L1 interference. In this respect, the interviewed teachers stated that the highest frequency of interference occurred in invented words, the position of adjectives, and word order. On the other hand, the lowest frequency occurred with the following variables: false cognates, misuse of comparatives and superlatives and misuse of gender forms.

In terms of teaching strategies to avoid Spanish interference, $23 \%$ of the teachers encouraged their students to read frequently; $22 \%$ of teachers used kinesthetic activities; $17 \%$ used bilingual dictionaries; $15 \%$ used English exclusively in the classroom; and $11 \%$ used translation exercises.

In this study, both high and low frequency interference errors were identified. High frequency interference errors included misuse of verbs $(20 \%)$, omission of personal and object pronouns $(16 \%)$, misuse of prepositions (11\%), overuse of articles (9\%), incorrect word order (9\%), and misuse of articles (5\%). Conversely, low frequency errors includedthe omission of prepositions (4\%), false cognates (4\%), the omission of articles $(3 \%)$, the misuse of personal and object pronouns (3\%), invented words $(3 \%)$, and poor noun concordance $(2 \%)$. Other variables, which are identified in this study as "Others" (see Fig. 1), had the lowest frequencies ( $2 \%$ or less), which 
included misuse of possessives, pluralization of adjectives, omission of verbs, incorrect position of adjectives, omission of possessives, misuse of intensifiers, misuse of negation, misuse of relative pronouns, overuse of personal and object pronouns, incorrect use of negation or double negation, orthographic errors, omission of nouns, omission of relative pronouns, and incorrect gender of nouns.

\section{Discussion}

\subsection{Quantitative Analysis}

Grammar structures and vocabulary were the most troublesome areas of language that Ecuadorian high-school students faced when writing in English. This is one of the main reasons for L 2 interference errors in this paper. A similar problem was found in a study conducted by Lopez (2011), in which grammar structures from the mother tongue were applied to texts that students wrote in the target language. In other words, there was a negative influence of Spanish (L1) on English (L2).

Based on this information, it could be inferred that when there is a gap in the student's knowledge during the writing stage in the target language, students tend to apply grammar rules from the L1.

In the present study, the overall perception of both teachers and students was that learners think in their mother tongue and then translate into English. As a result, translation causes considerable interference errors. This is supported by Bhela (1999), who states that learners translate their mother tongue structures at the moment of writing texts in the target language. Consequently, the interference of the L1 is considered negative as it impedes language acquisition of the L2.

With regard to vocabulary, Belha (1999) argues that learners not only take risks when writing in the target language, but also guess by using invented or borrowed words that are morphologically similar to words in their L1. Therefore, it is important to stress that interference errors arise because students use words that appear to have similar morphological structures to their L1. In fact, many such words have completely different meanings in the L2. Those words are referred to as false friends or false cognates.

The present study found that Ecuadorian students tend to invent words that do not exist in L2. It also shows that students do this when they do not know the right term in English to express an idea. However, the frequency of interference errors related to invented words and false cognates was minimal.

After analyzing the students' narrative passage, we concluded that the most common Spanish interference errors were the following: misuse of verbs, omission of personal and object pronouns, misuse of prepositions, overuse of articles, and poor/incorrect word order. On the other hand, we observed the lowest frequencies in variables such as omission of relative pronouns, nouns, possessives and verbs. Although these low frequencies showed that these errors were not very common, they cannot be ignored since they have a negative influence on developing writing skills in the L2.

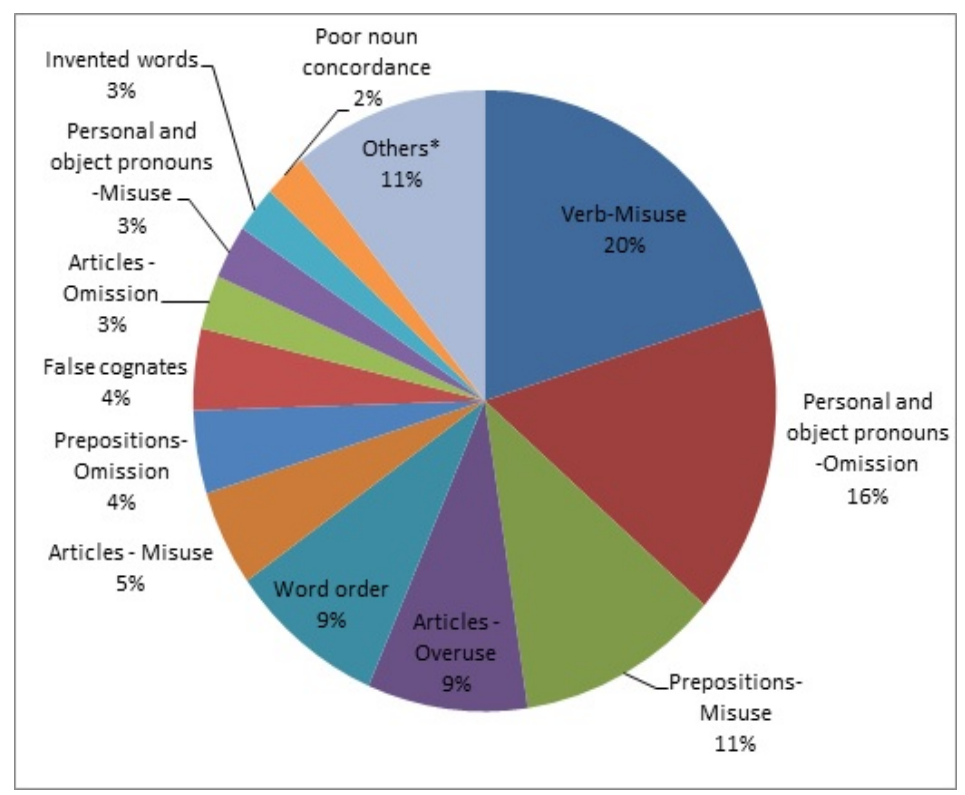

Figure 1. Most frequent interference errors found in the students' written work 
*Possessives-Misuse, Adjectives-Pluralization, Verbs-Omission, Adjectives-Position, Possessives-Omission, Intensifiers-Misuse, Negation-Misuse, Relative Pronouns-Misuse, Personal and Object Pronouns-Overuse, Negation-Double Negation, Orthographic, Nouns-Omission, Relative Pronouns-Omission, Nouns-Gender.

According to the teachers' responses, the highest frequencies of interference were present in the student's usage of invented words, the position of adjectives, and word order. These results significantly differ from the findings obtained in the students' writing tasks. However, the results from the teachers' questionnaire indicate that the lowest frequencies occurred with false cognates, the misuse of comparatives and superlatives, and the misuse of gender terms. These results were strikingly similar to those observed in the students' written passages.

\subsection{Qualitative Analysis}

First of all, it is worth mentioning that categorization of interference errors and their linguistic analysis has been used in studies such as the one carried out by Watcharapunyawong and Usaha (2013), who used error analysis of written texts and established categories as well as syntactic and semantic properties of L1 interference in writing. Likewise, Kaweera (2013) analyzed interference errors in English writing considering lexical, syntactic and discourse interference aspects. Based on this, the most frequent samples of interference errors from the students' written texts were qualitatively analyzed according to their semantic, syntactical and morphological features. The variables identifying the most frequent interference errors were misuse of verbs, omission of personal and object pronouns, misuse of prepositions, overuse of articles, and incorrect word order.

For the variable misuse of verbs, one of the examples found was the expression: "I learned a touch guitar." The interference error in this example constitutes the misuse of the verb touch, which is defined in the Oxford dictionary as: to put your hand or another part of your body onto somebody/something. The correct verb here would be play, which is used in this context to mean perform on a musical instrument. In this example, the student used the verb touch because there was interference from Spanish, i.e. where the verb tocar was used to mean "to feel something" or "to play an instrument".

Syntactically, the previous sample does not show a remarkable interference since it maintains the basic structure of the sentence (subject, verb and complement). It is not possible to identify a morphological error either. However, interference is evident in the semantic field. Therefore, the correct expression of this sentence can be achieved by using the correct verb in the infinitive form.

Another variable is the omission of personal and object pronouns. The following examples show errors of interference related to this variable:

"I like my childhood because was unusual and very amazing".

"I remember that played with the doll that my father bought me."

In the previous examples, the syntactical structures of the sentences are incorrect in English as the personal pronouns it and $I$ are omitted in the first and second sentences, respectively. This is a common interference error from the mother tongue, which is caused by the use of the tacit subject in Spanish.

Coral and Pérez (2004) observed that sentences in Spanish can sometimes use "a tacit subject". This implies that the subject may sometimes be omitted in the sentence when it is clearly understood in the context of the text or conversation. In this sense, it is not necessary to explicitly mention the subject.

The next most frequent variable is misuse of prepositions. The results show that Ecuadorian students often demonstrate interference problems with the use of prepositions. Khotaba (2013, p. 279) supports this view by stating that 'the occurrence of these errors relates basically to native language interference or the learners' knowledge inadequacy of the target language, or even the multiple meanings and functions of English prepositions." This type of interference can be observed in the following samples, which were obtained from the students' writing tasks:

"I go to the mountains in bicycle."

"In the 2003 go to Loja for the problem in my family."

In the above examples, a substitution of the prepositions in for by is evident. Furthermore, for is used instead of because of. In the first example, it occurs because it is common to use the preposition en in Spanish to express movement from one place to another by means of transport. Thus, in is the incorrect preposition. Furthermore, as we do not use this preposition in this particular context in English, the correct preposition has to be by.

In the second case, it was observed that students often get confused with the preposition for when they want to 
express a reason of something. This is a literal translation from Spanish because, in the L1, it is common to say "fui a Loja por un problema familiar". In this context, the correct preposition in English should be because of or due to.

Finally, it is necessary to mention that these examples contained neither morphological, nor syntactic interference errors.

The variable overuse of articles is another type of frequent interference error. Typical examples of sentences found in the students' written passages were:

"The Sunday I go to the Jipiro Park with my father and my mother."

"They get to the Ecuador in the 2001."

In the first case, the interference error arises as a result of the overuse of the article the. At the beginning of the sentence, the preposition on should be used instead of the. This common error is the result of the interference of the student's mother tongue, i.e. where the days of the week use the definite article $e l$ and not a preposition of time. In the second clause, the overuse of the article occurs because the Spanish rule states that general nouns are preceded by a definite article. Conversely, the English grammar rule for article usage states that theis not used with proper nouns, which in this case, is Jipiro park. On a syntactical level, it can be inferred that the sentence is mostly correct except for the extra articles, which do not fit in this sentence.

A similar situation was observed in the second example, i.e. where the definite article was used twice. In the first clause, the student wrote "the Ecuador". In English, the rule for using the article the states that it is not used with names of countries in the singular form. Whereas, in this context, the definite article can be used with names of countries in Spanish. Another error was found at the end of the sentence where the student wrote "in the 2001". This mistake is also the result of interference from the student's mother tongue since years uses a definite article in Spanish.For example, "en el 2001". In English, the definite article is not used with cardinal numbers. In this case, we are referring to a specific year.

Moreover, the sentence is correct from a syntactical view except for the extra article the, which is not necessary in this sentence. In addition, the main verb should be in the past tense.

Another variable found was word order. The following examples were gathered from the students' writing samples:

"I used to play with my brother soccer."

"My food favorite is sopa de tallarines."

By analyzing the first sentence, it can be observed that the sentence semantically conveys the right meaning. Therefore, the original sentence is semantically correct. On the other hand, the morphological analysis of the original sentence shows that eachlexical item in the sentence is correct (roots, suffixes, etc). Therefore, the original sentence is morphologically correct.

When we apply syntactical rules to the original sentence, it is evident that something does not fit here. In this case, the object of the verb play is the part that does not fit. In this particular sentence, the verb play is supposed to be followed by a direct object (play+soccer). Instead, the original sentence uses a verb that is followed by an indirect object (play+with my brother soccer).

The word order error identified in the first sentence therefore occurs as mother tongue interference. In fact, the sentence could have been written both ways by using play with a direct or an indirect object. For example, "Yo solía jugar con mi hermano fútbol", or "Yo solía jugar fútbol con mi hermano." Either way is acceptable in the L1.

In the second example, the morphological analysis shows that every single morpheme is correct, except for two words which were written in the student's mother tongue. On the other hand, the semantic analysis shows that the message that the writer wants to convey is straight-forward, except for the fact that the writer used two words in his/her mother tongue. It could be inferred that this occurred due to a lack of linguistic knowledge rather than L1 interference.

Finally, it is evident that the second sentence fails to be syntactically correct. At the beginning of the sentence, in the noun phrase "My food favorite..." there is a syntactical error which is identified as adjective misplacement. This type of error was identified as first language interference. In the writer's first language (Spanish) the adjective goes after the noun it modifies, for example, "comida favorita". For this reason, the writer wrote food favorite. The English grammar rule for the usage of adjectives states that the adjective goes before the noun it 
modifies. As described in the analysis above, this is a clear example of mother tongue interference.

After analyzing the results obtained from the teachers' and students' questionnaires as well as those of the students' written passages, it was necessary to inform the local body of high school teachers about the most common interference errors and to provide them with effective means of preventing such errors from occurring. In order to help teachers with this, we prepared a practical handout for the educational community, which contained some key strategies and suggestions on how to prevent L1 interference. Some examples of these strategies include the following: placing a greater emphasis on reading activities; using grammar exercises that focus on the most common interference errors; creating lists with the most common interference errors that students make in each lesson and using these to provide feedback; implementing contests or group activities to develop writing skills; using English in the classroom as much as possible; promoting the usage of English with English dictionaries; devoting class time to teaching about false cognates and words that are similar in meaning in both languages; and lastly, reinforcing writing skills in both the L1 and the L2.

\section{Conclusions}

The results from this study show that L1 causes interference in EFL learners when writing in English, which is often due to the fact that there is a linguistic transference from the native language to the target language.

English grammar and vocabulary were the areas that suffered the highest level of L1 language interference in local Ecuadorian EFL learners, that is, at the high school level. The students in this study thus rely heavily on Spanish grammar structures when writing a narrative passage in English. In addition, false cognates and invented words were the result of word-for-word translation from English into Spanish.

The variables indicate that the most frequent Spanish interference were misuse of verbs, omission of personal and object pronouns, misuse of prepositions, overuse of articles, and incorrect word order. It is important to mention that these errors mainly had a negative influence on developing writing skills in the target language.

The teachers and students interviewed for this study concurred that one of the strategies that learners use when writing in English was to think in the L1 and then to translate into English. This psycholinguistic phenomenon indicates that the influence of L1 on L2 causes significant interference when producing written texts in the L2.

Although the teachers in this study were aware of Spanish interference errors in English, it is evident that there is still a lack of strategies and activities being employed by teachers to prevent such errors from occurring. In order to respond to this problem, a practical handout was prepared to help teachers to improve their teaching methods and to inform them of potential L1 interference errors.

\section{Acknowledgements}

The authors would like to acknowledge Universidad Técnica Particular de Loja authorities for promoting and funding our research. Likewise, the contribution of the principals, teachers and students of the participating institutions is deeply appreciated.

\section{References}

Akram, A., \& Malik, A. (2010). Integration of language learning skills in second language acquisition. International Journal of Arts and Sciences, 3(14), 2. Retrieved from http://www.openaccesslibrary.org/images/PRV127_Aneela_Akram.pdf

Alonso, M. (1997). Language transfer: Interlingual errors in Spanish students of English as a foreign language. Revista Alicantina de Estudios Ingleses, 10, 7-14. Retrieved from http://rua.ua.es/dspace/bitstream/10045/5990/1/RAEI_10_01.pdf

Beardsmore, H. B. (1982). Bilingualism: Basic principles. Tieto: Avon.

Bhela, B. (1999). Native language interference in learning a second language: Exploratory case studies of native language interference with target language usage. International Education Journal, 1(1), 22-31. Retrieved from http://ehlt.flinders.edu.au/education/iej/articles/v1n1/bhela/bhela.pdf

Berthold, M., Mangubhai, F., \& Batorowicz, K. (1997). Bilingualism \& multiculturalism: Study book. University of Southern Queensland: Toowoomba, QLD.

Calvo, N. (2005). Negative language transfer when learning Spanish as a foreign language. Interlingüistica, 16(1), 237-248. Retrieved from http://www.google.com.ec/url?sa=t\&rct=j\&q=\&esrc=s\&source=web\&cd $=1 \&$ ved $=0 \mathrm{CCgQFjAA} \& u r l=\mathrm{http} \% 3 \mathrm{~A} \% 2 \mathrm{~F} \% 2 \mathrm{Fdialnet}$.unirioja.es\%2Fdescarga\%2Farticulo\%2F 2514223.pd f\&ei=ni1hU5ngII3isASGzoKwCg\&usg=AFQjCNE3scyy7B1X2zQnMPsHhPojJeVU5g\&bvm=bv.6563607 0, d.cWc 
Coral, K., \& Pérez, J. (2004). Manual de gramática del castellano: Variedad estándar y usos regionales (1st ed.). Lima: Proeduca-GTZ.

Dam, P. (2010). Mother-tongue interference in Spanish-speaking English language learners' interlanguage. Retrieved from http://www.viethoc.com/Ti-Liu/bien-khao/khao-luan/mother-tongueinterferenceinspanishspeakingenglishlanguagelearners $\% \mathrm{E} 2 \% 80 \% 99$ interlanguage

Ellis, R. (1997). Second language acquisition. Oxford: Oxford University Press.

Hancock, B., Ockleford, E., \& Windridge, K. (2009). An introduction to qualitative research. Sheffield: The NIHR Research Design Service for Yorkshire \& the Humber.

Harmer, J. (2004). How to teach writing. England: Pearson Education Limited.

József, H. (2001). Advanced writing in English as a foreign language: A corpus-based study of processes and products. Pécs: Lingua Franca Csoport.

Kaweera, C. (2013). Writing error: A review of interlingual and intralingual interference in EFL context. English Language Teaching, 6(7), 9-18. http://dx.doi.org/10.5539/elt.v6n7p9

Khotaba, E. (2013). Errors in the use of prepositions and adverb particles by Arab ESL speakers: Performance analysis. International Journal of Linguistics, 5(1), 273-282. http://dx.doi.org/10.5296/ijl.v5i1.3310

Kroll, B. (2003). Exploring the dynamics of second language writing. USA: Cambridge University Press.

Lopez, J. (2011). Spanish-English writing structure interferences in second language learners. Gist Education and Learning Research Journal, 5, 158-179. Retrieved from http://gisteducation.weebly.com/uploads /7/9/2/8/7928165/spanish-english_writing_structure_interferences_in_second_language_learners.pdf

Nunan, D. (1999). Second Language Teaching and Learning. Boston: Thomson/Heinle.

Teddlie, C., \& Yu, F. (2007). Mixed methods sampling: A typology with examples. Journal of Mixed Methods Research, 1(1), 79. Retrieved from http://www.sagepub.com/foundations/includes/jmmr_journal.pdf

Watcharapunyawong, S., \& Usaha, S. (2013). Thai EFL students' writing errors in different text types: The interference of the first language. English Language Teaching, 6(1), 67-68. http://dx.doi.org/10.5539/elt.v6n1p67

\section{Copyrights}

Copyright for this article is retained by the author(s), with first publication rights granted to the journal.

This is an open-access article distributed under the terms and conditions of the Creative Commons Attribution license (http://creativecommons.org/licenses/by/3.0/). 